\title{
LETTERS
}

\section{Directly Observed Care: Can Unannounced Standardized Patients Address a Gap in Performance Measurement?}

\author{
Sondra Zabar, $\mathrm{MD}^{7}$, Colleen Gillespie, $\mathrm{PhD}^{2}$, Kathleen Hanley, $\mathrm{MD}^{7}$, and Adina Kalet, $\mathrm{MD}, \mathrm{MPH}^{\top}$ \\ 'Department of Medicine, Division of General Internal Medicine, New York University School of Medicine, New York, NY, USA; ${ }^{2}$ Department of \\ Medicine, Division of General Internal Medicine and Institute for Innovations in Medical Education, New York University School of Medicine, New \\ York, NY, USA.
}

J Gen Intern Med 29(11): 1439

DOI: $10.1007 / \mathrm{s} 11606-014-3004-9$

(c) Society of General Internal Medicine 2014

To The Editor: Weiner and Schwartz have done an outstanding job in framing both the potential of and challenges associated with the use of unannounced standardized patients (USPs) for assessing quality of care. ${ }^{1}$ We strongly believe that health care systems and medical educators are just beginning to unlock the potential of USPs and that the barriers can and are already being addressed through creative and collaborative problem-solving. With AHRQ funding focused on simulation and outpatient safety, and in partnership with a large, urban hospital, we have been able to design and implement a USP program (totaling more than 300 USP visits) that provides hospital leadership with ongoing data on clinic functioning. ${ }^{2}$ In addition, we are exploring the relationship between Objective Structured Clinical Exams and USP-assessed performances among internal medicine residents to better understand what each can tell us about resident competence and professionalism as well as the influence of clinic variables on provider behavior or quality of care. Through chart review of USP visit notes (that are based on standardized clinical portrayals), we have been able to assess the quality of residents' documentation, measure variation in treatment, and identify critical safety issues. ${ }^{3}$ We encourage others to find new ways to harness this versatile tool for improving the quality of care and enhancing the impact of education.

Corresponding Author: Sondra Zabar, MD; Department of Medicine, Division of General Internal MedicineNew York University School of Medicine, New York, NY 10016, USA (e-mail: Sondra.Zabar@nyumc.org).

\section{REFERENCES}

1. Weiner S, Schwartz A. Directly observed care: can unannounced standardized patients address a gap in performance measurement? Journal of General Internal Medicine. 2014;29(8):1183-7.

2. Zabar S, Hanley K, Stevens, Murphy J, Burgess A, Kalet A, Gillespie C. Unannounced standardized patients: a promising method of assessing patient-centered care in your health care system. BMC Health Services Research. 2014;14:157.

3. Zabar S, Ark T, Gillespie C, Hsieh A, Kalet A, Kachur E, Manko J, Regan L. Unannounced standardized patients assess professionalism and communication skills in the emergency department? Academic Emergency Medicine. 2009;16(9):915. 